\title{
Cytochrome $c$ Oxidase as a Cause of Variation in Oxygen Uptake Rates Among Vegetables
}

\author{
Yoshio Makinoㅁ, Masayuki Ichimura, Yoshinori Kawagoe, and Seiichi Oshita \\ Graduate School of Agricultural and Life Sciences, The University of Tokyo, Yayoi 1-1-1, Bunkyo-ku, \\ Tokyo 113-8657, Japan
}

\begin{abstract}
AdDITIONAL INDEX wORDs. enzymatic activity, image analysis, staining, Brassica oleracea, Spinacia oleracea, Allium cepa
Abstract. The effect of cytochrome $c$ oxidase, the terminal oxidase in the respiratory chain, on $\mathrm{O}_{2}$ uptake by vegetables was investigated. Broccoli florets (Brassica oleracea L. var. italica Plenck), spinach leaves (Spinacia oleracea $\mathrm{L}$.), and onion bulbs (Allium cepa $\mathrm{L}$.), which were expected to show rapid, moderate, and slow $\mathrm{O}_{2}$ uptake rates, respectively, were used in the current study. The order of $\mathrm{O}_{2}$ uptake rate measured by a closed method with a gas chromatograph was broccoli florets $>$ spinach leaves $>$ onion bulbs. Cytochrome $c$ oxidase activity of mitochondrial preparations from onion bulbs was lower than that of the other vegetables, as was the $\mathrm{O}_{2}$ uptake rate. The higher $\mathrm{O}_{2}$ uptake rate of broccoli florets compared to spinach leaves was caused by higher cytochrome $c$ oxidase activity of the floral buds. Grayscale luminance was used to determine the extent and distribution of staining in the tissues due to cytochrome $c$ oxidase activity. Active $\mathrm{O}_{2}$ uptake by floral buds of broccoli florets was caused by the high concentration of cytochrome $c$ oxidase in the pistil and petal. The absorbance of stems of broccoli florets at $823 \mathrm{~nm}$, possibly derived from absorption by copper in cytochrome $c$ oxidase, was higher than that of onion scale leaves, which agreed with the results of cytochrome $c$ oxidase staining. We concluded that cytochrome $c$ oxidase contributed to the $\mathrm{O}_{2}$ uptake rate by vegetables and that cytochrome $c$ oxidase was one of the important causes for variation in $\mathrm{O}_{2}$ uptake rates among vegetables.
\end{abstract}

Respiration of horticultural products after harvest often seriously damages their quality by consuming nutrients such as carbohydrates, organic acids, and fatty acids. According to Robinson et al. (1975), a commodity with rapid respiration tends to senesce earlier. We derived an $\mathrm{O}_{2}$ uptake rate equation of horticultural products based on Langmuir's adsorption theory and Eyring's transition-state theory (Makino et al., 1997), in which we suggested that $\mathrm{O}_{2}$ uptake rate increases with the number of $\mathrm{O}_{2}$ adsorption sites per unit mass, which is dependent on the kind of horticultural product. On the other hand, $>90 \%$ of $\mathrm{O}_{2}$ molecules taken up by a living cell are consumed at the active site of cytochrome $c$ oxidase (EC 1.9.3.1), which is the terminal oxidase of the respiratory chain and is buried in the mitochondrial inner membrane (Alberts et al., 1994). These reports (Alberts et al., 1994; Makino et al., 1997) suggest that cytochrome $c$ oxidase is one of the most important $\mathrm{O}_{2}$ adsorption sites. This also suggests that the $\mathrm{O}_{2}$ uptake rate of a horticultural product will correspond to the number of active sites of cytochrome $c$ oxidase per mass (equivalent to cytochrome $c$ oxidase concentration). A huge number of respiration (including $\mathrm{O}_{2}$ uptake) rate data for horticultural products has been published (Fonseca et al., 2002). However, no report has been found concerning the effect of cytochrome $c$ oxidase concentration on $\mathrm{O}_{2}$ uptake rate in vegetables.

In the current study, we attempted to estimate cytochrome $c$ oxidase concentration in three kinds of vegetables expected to show different respiration rates by three methods of cytochrome $c$ oxidase activity measurement: assay kit, cytochrome

Received for publication 2 Aug. 2006. Accepted for publication 14 Dec. 2006. Keiko Ohashi-Kaneko on our faculty loaned several pieces of equipment to us for experiments. Yoko Hoshi of the Tokyo Institute of Psychiatry introduced the cytochrome $c$ oxidase staining method to us. The authors express sincere thanks to them.

${ }^{1}$ Corresponding author. E-mail: amakino@mail.ecc.u-tokyo.ac.jp. $c$ oxidase staining, which is predominantly used for detecting cytochrome $c$ oxidase activity in the brains of animals (Shoham et al., 1997), and detection of the difference of cytochrome $c$ oxidase concentration in vegetable tissues by spectrophotometry, a noninvasive measurement used for evaluating $\mathrm{O}_{2}$ sufficiency of cytochrome $c$ oxidase in cephalo of cats (Felis silvestris Schreber F. catus L.) (Jöbsis, 1977). The objective of the current study was to validate the assumption that the $\mathrm{O}_{2}$ uptake rate of vegetables increases with the number of $\mathrm{O}_{2}$ adsorption sites per mass, which is dominated by cytochrome $c$ oxidase concentration, and that the number of $\mathrm{O}_{2}$ adsorption sites per mass varies depending on the kind of horticultural product, as we suggested (Makino et al., 1997) on the basis of earlier experimental results.

\section{Materials and Methods}

Vegetables. Broccoli florets (cv. Naomidori) (398 and $405 \mathrm{~g}$ ), bunches of spinach leaves (cv. Bullitt) (31.3 and 42.2 g), and onion bulbs (cv. Kunnepu) $(261,288$, and $328 \mathrm{~g}$ ) were purchased at the Metropolitan Central Wholesale Market in Tokyo. Vegetables with representative appearance were selected as samples from the commodities that arrived at the market in the morning on the day of experiments. These vegetables are normally expected to show rapid, moderate, and slow respiration, respectively (Robinson et al., 1975). In the current study, the number of samples was restricted to avoid denaturation of the samples during experimental treatment, because many kinds of measurements have to be done for each individual sample in a short period to assure an accurate data set. The vegetables were stored for $3 \mathrm{~h}$ at $20^{\circ} \mathrm{C}$ before the series of measurements.

Respiration rate measurement. The $\mathrm{O}_{2}$ uptake and $\mathrm{CO}_{2}$ production rates of the vegetables were measured by the closed method described in Fonseca et al. (2002). It was important to 
relate $\mathrm{O}_{2}$ uptake rate to cytochrome $c$ oxidase concentrations estimated by two methods. On the other hand, $\mathrm{CO}_{2}$ production rates are usually similar to $\mathrm{O}_{2}$ uptake rates (Kader et al., 1989), so these were measured to confirm the validity of $\mathrm{O}_{2}$ uptake rate data. We compared $\mathrm{CO}_{2}$ production rates obtained in the current study with published $\mathrm{CO}_{2}$ production rates (Robinson et al., 1975).

A broccoli floret was enclosed in a 2.1-L stainless steel jar and stored at $20^{\circ} \mathrm{C}$. This temperature was selected to compare the data with the values reported by Robinson et al. (1975). A $0.5-\mathrm{mL}$ aliquot of gas in the jar was sampled with a gas-tight syringe through a silicon rubber septum $1 \mathrm{~h}$ after enclosure. Oxygen concentration in the sampled gas was measured using a GC-14A gas chromatograph (Shimadzu Co., Kyoto, Japan) equipped with a thermal conductivity detector and run under the following conditions: column temperature, $50{ }^{\circ} \mathrm{C}$; bridge current, $80 \mathrm{~mA}$; carrier gas $(\mathrm{He})$ pressure, $247 \mathrm{kPa}$; column and detector temperatures, $100{ }^{\circ} \mathrm{C}$. A 2-m molecular sieve 5A-packed column (GL Sciences, Tokyo) was used. Carbon dioxide concentration was measured by gas chromatography under the following conditions: column temperature, $50{ }^{\circ} \mathrm{C}$; bridge current, $120 \mathrm{~mA}$; carrier gas $(\mathrm{He})$ pressure, $210 \mathrm{kPa}$; column and detector temperatures, $100^{\circ} \mathrm{C}$. A 2-m Gaskuropack-54-packed column (GL Sciences) was used. The same jar and methods were used to measure the $\mathrm{O}_{2}$ and $\mathrm{CO}_{2}$ concentrations of spinach leaves. The storage time was $4 \mathrm{~h}$ because the $\mathrm{O}_{2}$ uptake and $\mathrm{CO}_{2}$ production rates of spinach leaves were assumed to be much lower than broccoli florets (Robinson et al., 1975). An onion bulb was enclosed in a $0.76-\mathrm{L}$ acrylic jar and stored at $20^{\circ} \mathrm{C}$. A $0.5-\mathrm{mL}$ aliquot of gas in the jar was sampled through a silicon rubber septum $4 \mathrm{~h}$ after enclosure, and the $\mathrm{O}_{2}$ and $\mathrm{CO}_{2}$ concentrations were measured by the same methods. Oxygen uptake and $\mathrm{CO}_{2}$ production rates of the vegetables were calculated from the difference in $\mathrm{O}_{2}$ and $\mathrm{CO}_{2}$ concentrations before (the same as breathing air) and after storage.

Mitochondrial extraction. Samples were collected from the middle longitudinal site of a main stem and floral buds of a broccoli floret, the middle site of a spinach leaf, and the fourth scale leaf from the center of an onion bulb split in two at the equator. In the case of broccoli florets, the activity was measured separately for stems and for floral buds because the activity of the floral buds is predominantly due to active young cells and so might be much higher than that of the stems. The samples were frozen in liquid nitrogen immediately after sampling and ground using a frozen cell crusher. Mitochondria in the vegetable tissues were isolated using a mitochondria isolation kit (Sigma-Aldrich, St. Louis) from a prepared 0.1-g sample in a $1.5-\mathrm{mL}$ microtube according to the protocol supplied with the kit.

Cytochrome $C$ oxidase activity measurement. Cytochrome $c$ oxidase activity was assayed by monitoring the decrease in absorbance of ferrocytochrome $c$ measured at $550 \mathrm{~nm}$ caused by its oxidation to ferricytochrome $c$ by cytochrome $c$ oxidase according to the protocol described in the cytochrome $c$ assay kit (Sigma-Aldrich). A 20- $\mu \mathrm{L}$ mitochondrial preparation was then used as a sample, and the reaction temperature was fixed at $20^{\circ} \mathrm{C}$, which was the same as that used to determine the $\mathrm{O}_{2}$ uptake rate by gas chromatography. Cytochrome $c$ oxidase activity [microkatals per kilogram $\left.\left(\mu \mathrm{kat} \cdot \mathrm{kg}^{-1}\right)\right]$ was measured in duplicate for an individual product (four or six measurements per vegetable). Oxygen molecules taken up in a living cell are consumed for the oxidation of $\mathrm{H}^{+}$by cytochrome $c$ oxidase as shown in the following chemical equation (Yonetani and Ray, 1965):

$$
\text { ferrocytochrome } c+1 / 4 \mathrm{O}_{2}+\mathrm{e}^{-}+\mathrm{H}^{+} \stackrel{\begin{array}{c}
\text { cytochrome } c \\
\text { oxidase }
\end{array}}{\text { ferricytochrome } c+1 / 2 \mathrm{H}_{2} \mathrm{O}}
$$

Oxygen uptake rates were calculated by multiplying cytochrome $c$ oxidase activity by the constant 28.8 .

Cytochrome $C$ oxidase staining. Distribution of cytochrome $c$ oxidase in the vegetable cells was evaluated based on the procedure of Wong-Riley (1979). The samples were collected from the same sites used for mitochondrial extraction. The sample tissues were immediately fixed with a mixture of paraformaldehyde $(4 \%)$ and glutaraldehyde $(1 \%)$ in $0.1 \mathrm{M}$ phosphate buffer, $\mathrm{pH} 7.4$, and $4 \%$ sucrose for $1 \mathrm{~h}$ at $4{ }^{\circ} \mathrm{C}$. The fixed tissues were immersed in $30 \%$ sucrose for $2 \mathrm{~d}$ at $4{ }^{\circ} \mathrm{C}$ and frozen at $-80{ }^{\circ} \mathrm{C}$ after treatment. The samples were embedded in a natural resin (Canada balsam) and sectioned at a thickness of $25 \mu \mathrm{m}$ by a freezing microtome. The sections were immersed in a solution including $60 \mathrm{mg}$ 3,3-diaminobenzidine tetrahydrochloride, $27 \mathrm{~mL}$ sodium acetate $(0.1 \mathrm{M}), 3 \mathrm{~mL}$ manganese chloride ( $1 \%)$, and $0.3 \mathrm{~mL} \mathrm{H}_{2} \mathrm{O}_{2}(0.1 \%)$ for $1 \mathrm{~h}$ at $37{ }^{\circ} \mathrm{C}$, rinsed twice, and developed with $30 \mathrm{~mL}$ of a copper sulfate solution (1\%). The brown color indicates cytochrome $c$ oxidase activity. The section was then rinsed again and dehydrated with alcohol. It was mounted on a glass slide after air-drying. Staining and preparation of mounted sections were performed by NAC Co. Ltd. (Tokyo).

IMAGE ANALYSIS OF STAINED CYTOCHROME $\boldsymbol{C}$ OXIDASE. The sections stained for cytochrome $c$ oxidase were observed using a DMLM/LP optical microscope (Leica Microsystems Japan Co. Ltd., Tokyo), and the degree of staining was measured by image analysis using a DFC320 digital color camera system (Leica Microsystems Japan Co. Ltd.). All images used for the analysis of cytochrome $c$ oxidase staining were taken under the same optical conditions to avoid variance in intensity depending on image acquisition conditions. The observed objects were zoomed 25- or 100-fold, and images were taken under the same white balance, iris, and exposure conditions at each magnification. The resolution of 100-fold zoomed images used for image analysis obtained by the system was $538 \mathrm{~nm} /$ pixel, where 8-bit data were allocated to red, green, and blue channels. The average luminance per cell in the tone ranges from 0 to 255 , correlating with cytochrome $c$ oxidase staining intensity, and the area of selected sites per cell were measured after the images were transformed into grayscale using Photoshop ${ }^{\circledR}$ (version 9.0; Adobe Systems Inc., San Jose, Calif.). We selected 19-70 cells (cytoplasm) per organ from onion scale leaves, leaf lamina of spinach, and stems and floral buds of broccoli florets.

SPECTROPHотомetry. This measurement was performed to investigate whether cytochrome $c$ oxidase concentration in vegetable tissues could be detected by a non-destructive method or not. A portable FQA-NIR-GUN spectrophotometer (FANTEC Research Institute and International, Kosai, Japan) was used for measurement of the diffuse reflectance spectrum of vegetables in the range from 588.2 to $1091.7 \mathrm{~nm}$. The main stems of broccoli florets and onion bulbs with the outer skin removed were selected for measurement because both are composed of thick flesh useful for the measurement of diffuse reflectance. The diffuse reflectance was measured six times per 
product. This measurement was not applied to spinach leaves because the form of the measurement site of the spectrophotometer was not suitable for thin tissues.

Statistical analysis. Experimental data were analyzed using one-way analysis of variance (ANOVA). When between-class variation was significant at $P<0.05$, the mean values were compared by the least significant difference (LSD) test $(P<0.05)$ or the Tukey-Kramer honestly significant difference (HSD) test $(P<0.05)$. JMP (version 6.0; SAS Institute, Cary, N.C.) was used for statistical analysis.

\section{Results}

RESPIRATION RATE. Respiration rates for broccoli florets, spinach leaves, and onion bulbs are presented in Table 1. It was confirmed by statistical analysis that $\mathrm{O}_{2}$ uptake and $\mathrm{CO}_{2}$ production rates of the examined vegetables were significantly different from each other. This indicates that the samples examined are appropriate for evaluating the effect of cytochrome $c$ oxidase on $\mathrm{O}_{2}$ uptake rate. The order of $\mathrm{O}_{2}$ uptake or $\mathrm{CO}_{2}$ production rate was broccoli florets $>$ spinach leaves $>$ onion bulbs (Table 1). All respiratory quotients (RQ) were almost unity. According to Kader et al. (1989), RQ ranges from 0.7 to 1.3 under aerobic conditions. Therefore, $\mathrm{O}_{2}$ uptake rates were feasible to measure without causing any physiological disorder.

Cytochrome $C$ oxidase ACTIVITY. Cytochrome $c$ oxidase activity and $\mathrm{O}_{2}$ uptake rate of mitochondrial preparations from vegetables measured by the cytochrome $c$ assay kit were in the order of floral buds (broccoli florets) $>$ stems (broccoli florets) $\approx$ spinach leaves $>$ onion bulbs, as presented in Table 2 .

Cytochrome $\boldsymbol{C}$ OXIDASE STAINING. Typical appearances of cytochrome $c$ oxidase staining of vegetable tissues are shown in Fig. 1. These are 25-fold zoomed images of the objects. This appears to be the first report concerning cytochrome $c$ oxidase staining of plant cells while cytochrome $c$ oxidase staining has been frequently applied to investigate the distribution of

Table 1. Respiration rate for whole vegetable products measured by a closed method and GC. ${ }^{\mathrm{z}}$

\begin{tabular}{lccc}
\hline Product & $\begin{array}{c}\mathrm{O}_{2} \text { uptake rate } \\
\left(\mathrm{mg} \cdot \mathrm{kg}^{-1} \cdot \mathrm{h}^{-1}\right)\end{array}$ & $\begin{array}{c}\mathrm{CO}_{2} \text { production } \\
\text { rate }\left(\mathrm{mg} \cdot \mathrm{kg}^{-1} \cdot \mathrm{h}^{-1}\right)\end{array}$ & $\begin{array}{c}\text { Respiratory } \\
\text { quotient }\end{array}$ \\
\hline Onion bulb & $4.2 \mathrm{a}$ & $5.3 \mathrm{a}$ & $0.92 \mathrm{a}$ \\
Spinach leaf & $101 \mathrm{~b}$ & $134 \mathrm{~b}$ & $0.96 \mathrm{a}$ \\
Broccoli floret & $182 \mathrm{c}$ & $254 \mathrm{c}$ & $1.01 \mathrm{a}$ \\
\hline
\end{tabular}

${ }^{\mathrm{z}}$ Values within a column followed by the same lowercase letter are not significantly different $(P<0.05)$ according to the least significant difference (LSD) test.

Table 2. Cytochrome $c$ oxidase activity in vegetables. ${ }^{\mathrm{z}}$

\begin{tabular}{llcc}
\hline Product & Organ & $\begin{array}{c}\text { Ferrocytochrome } c \\
\text { oxidation activity } \\
\left(\mu \mathrm{kat} \cdot \mathrm{kg}^{-1}\right)\end{array}$ & $\begin{array}{c}\mathrm{O}_{2} \text { uptake rate } \\
\left(\mathrm{mg} \cdot \mathrm{kg}^{-1} \cdot \mathrm{h}^{-1}\right)\end{array}$ \\
\hline Onion bulb & Scale leaf & $0.052 \mathrm{ac}$ & $1.5 \mathrm{a}$ \\
Spinach leaf & Leaf & $0.72 \mathrm{bc}$ & $20.7 \mathrm{~b}$ \\
Broccoli floret & Stem & $0.801 \mathrm{bc}$ & $23.3 \mathrm{bc}$ \\
& Floral bud & $1.46 \mathrm{cc}$ & $42.0 \mathrm{c}$ \\
\hline
\end{tabular}

${ }^{\mathrm{z}}$ Values within a column followed by the same lowercase letter are not significantly different $(P<0.05)$ according to the least significant difference (LSD) test. cytochrome $c$ oxidase in animal brains (Dali et al., 1997; Shoham et al., 1997; Wong-Riley, 1979). Images of the prepared sections mentioned above were quantified by image analysis. The average values of the cross-sectional area per cell and grayscale luminance per cell are presented in Table 3. According to the stained cross section of the lamina of spinach leaves, although a dark vascular bundle was observed, vessels and phloem were not stained and intercellular space was darkly stained. Cytochrome $c$ oxidase does not exist in the cell wall or intercellular space, but it exists in the inner membrane of mitochondria (Alberts et al., 1994). This suggests that the brown pigment is deposited in the narrow intercellular space and is not deposited in the larger airspace. This also indicates that selection of cellular cytoplasm, distinguished from cell wall and intercellular space, was preferable for evaluation of staining intensity by image analysis. Therefore, the stained intercellular space and cell wall were excluded from image analysis.

Absorption Spectra. The second derivatives with respect to wavelength of absorption spectra of onion scale leaves and main stems of broccoli florets $\approx 830 \mathrm{~nm}$ are shown in Fig. 3. An absorption band was observed at $823 \mathrm{~nm}$. Mean second derivatives of absorbance at $823 \mathrm{~nm}$ were $-3.6 \times 10^{-3}$ for onion scale leaves and $-4.7 \times 10^{-3}$ for main stems of broccoli florets; these values were significantly different at $P<0.05$ by one-way ANOVA with the LSD test. This indicates that the absorbance of broccoli floret stems was higher than that of onion scale leaves because the second derivative of absorbance decreases with the increase of original absorbance.

\section{Discussion}

RELATIONSHIP BETWEEN CYTOCHROME $C$ OXIDASE ACTIVITY AND CONCENTRATION. Enzymatic activity of a molecule of cytochrome $c$ oxidase is affected by reaction conditions around the enzyme. Based on the activity of cytochrome $c$ oxidase extracted from sweet corn (Zea mays L.) and cassava root (Manihot esculenta Crantz.) (Maeshima and Asahi, 1978; Maeshima et al., 1980), the conditions especially affecting cytochrome $c$ oxidase activity are temperature and $\mathrm{pH}$. Vegetables are slightly acidic at $\mathrm{pH}$ of $\approx 6.0$ (Artés et al., 2001; Karovičová et al., 1999; Lee and Parkin, 1998). Tajima (1965) reported that cytochrome $c$ oxidase activity per unit mass measured in mitochondrial preparations from orchard grass (Dactylis glomerata L.) and rice root (Oryza sativa L.) was inhibited by treatment for $3 \mathrm{~h}$ at 32 and $35^{\circ} \mathrm{C}$, respectively. The reaction temperature was fixed at $20{ }^{\circ} \mathrm{C}$ in the current study to compare the cytochrome $c$ oxidase activity to $\mathrm{O}_{2}$ uptake rate measured by gas chromatography.

Ethylene is a known aging hormone that promotes enzymatic activities or respiration in horticultural products (Bleecker and Kende, 2000). Its presence is commonly needed for fruit ripening during the climacteric rise (Bleecker and Kende, 2000). This suggests that the influence of ethylene on enzymatic activities in vegetables is lower than that in fruits. According to enzyme kinetics as proposed by Michaelis and Menten (1913), the sum of enzymatic activity in a reaction system increases with the concentration of enzyme because the conditions affecting enzymatic reaction rate such as temperature, $\mathrm{pH}$, and ethylene production were not different among the examined vegetables as mentioned above. Therefore, 

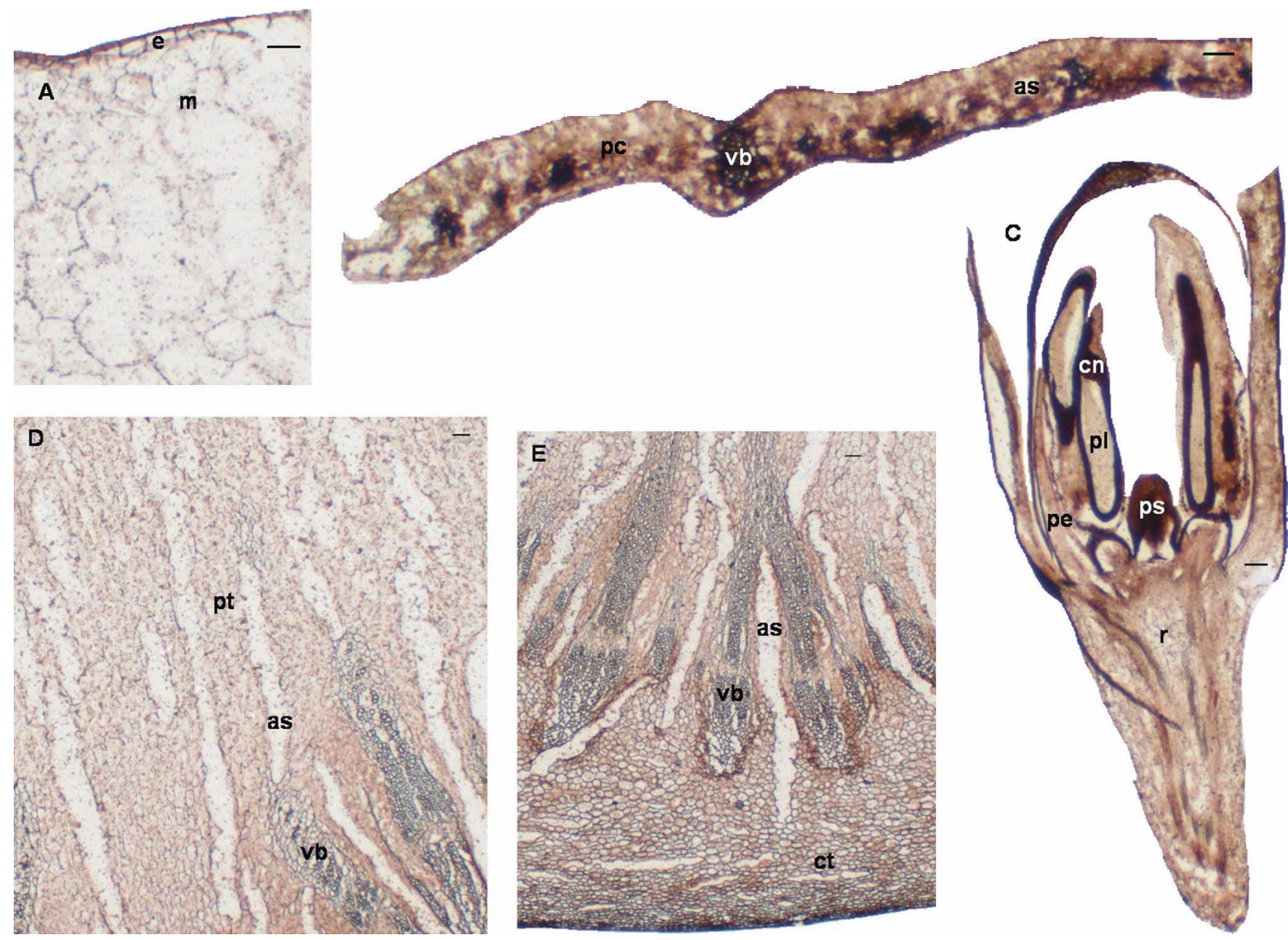

Fig. 1. Typical appearance of cytochrome $c$ oxidase staining for (A) an onion scale leaf, (B) lamina of a spinach leaf, (C) a floral bud of a broccoli floret, (D) part of a central cylinder of a broccoli floret stem, and $(\mathbf{E})$ part of an epidermal system. In the images $(\mathrm{scale}=50 \mu \mathrm{m})$, epidermis $=\mathrm{e}$, mesophyll $=\mathrm{m}$, upper epidermis $=\mathrm{ue}$, lower epidermis $=1$, air space $=\mathrm{as}$, parenchyma cell $=\mathrm{pc}$, vascular bundle $=\mathrm{vb}, \mathrm{pith}=\mathrm{pt}, \mathrm{cortex}=\mathrm{ct}, \mathrm{pistil}=\mathrm{ps}$, connective tissue $=\mathrm{cn}$, pollen $=\mathrm{pl}, \mathrm{petal}=\mathrm{pe}$, and receptacle $=\mathrm{r}$.

cytochrome $c$ oxidase activity per mass measured in the current study was equivalent to cytochrome $c$ oxidase concentration.

OXYGEN UPTAKE RATES MEASURED BY IN SITU AND IN VITRO METHODS. The differences in the $\mathrm{O}_{2}$ uptake rate measured by gas chromatography and calculated from cytochrome $c$ oxidase activity may be caused by the difference in experimental method and the state of the sample (whole product or mitochondrial preparation). Oxygen uptake rates calculated from oxidase activity were 2.8-5.5 times lower than rates measured with gas chromatography. The $\mathrm{O}_{2}$ uptake rate determined by gas chromatography measured in situ may include $\mathrm{O}_{2}$ uptake by an alternative oxidase (Juszczuk and Rychter, 2003), polyphenol oxidase, or other $\mathrm{O}_{2}$-reduction system (Kader, 1986) as well as that due to cytochrome $c$ oxidase. On the other hand, $\mathrm{O}_{2}$ uptake rates calculated from in vitro cytochrome $c$ oxidase activity express $\mathrm{O}_{2}$ uptake by cytochrome $c$ oxidase only. Yoshikawa (2002) described deactivation or reduction of cytochrome $c$ oxidase activity during extraction and purification of the enzyme. All of the above could have contributed to the difference between $\mathrm{O}_{2}$ uptake rate measured by gas chromatography and that calculated from cytochrome $c$ oxidase activity. However, the $\mathrm{O}_{2}$ uptake rate calculated from cyto- chrome $c$ oxidase activity was effective for estimating the $\mathrm{O}_{2}$ uptake rate measured by gas chromatography of vegetables because the order of the activity values agreed with the order of $\mathrm{O}_{2}$ uptake rate measured by gas chromatography. The results supported the rate of vegetable $\mathrm{O}_{2}$ uptake being affected by cytochrome $c$ oxidase concentration.

CONTRIBUTION OF CYTOCHROME $C$ OXIDASE TO $\mathrm{O}_{2}$ UPTAKE BY VEGETABLES. Cytochrome $c$ oxidase activity of onion bulbs was significantly lower than that of the other vegetables. The luminance of the mesophyll of onion scale leaves was highest among the stained organs (Table 3 ). However, the luminance of the epidermis of onion scale leaves was not significantly different from that of spinach leaf epidermis, floral bud petals of broccoli florets, or mid-epidermis $(0.02-0.2 \mathrm{~mm}$ from the edge) of broccoli floret stems. Hence the cytochrome $c$ oxidase concentration of onion bulbs is lower than that of the other vegetables because the contribution to the cross-sectional area of the epidermal cells in a scale leaf is negligible compared with the mesophyll (thickness of an epidermal cell is $\approx 0.5 \%$ of a scale leaf). This staining result supported the low $\mathrm{O}_{2}$ uptake rate measured by gas chromatography of onion bulbs being caused by low cytochrome $c$ oxidase concentration in the mesophyll. 
Table 3. Grayscale luminance and cross-sectional area of a vegetable cell (cytoplasm) determined by image analysis. ${ }^{z}$

\begin{tabular}{llrr}
\hline \multirow{2}{*}{ Product } & \multicolumn{1}{c}{ Organ } & Luminance & $\begin{array}{r}\text { Cross-sectional } \\
\text { area }\left(\mathrm{m}^{2} \times 10^{-11}\right)\end{array}$ \\
\hline Onion bulb & Mesophyll of a scale leaf & $230 \mathrm{ac}$ & $1,055 \mathrm{ac}$ \\
Spinach leaf & Epidermis of a scale leaf & $124 \mathrm{ef}$ & $93 \mathrm{bc}$ \\
& Parenchyma cell & $144 \mathrm{dc}$ & $60 \mathrm{cc}$ \\
Stem of broccoli floret & Epidermis & $134 \mathrm{de}$ & $48 \mathrm{cc}$ \\
& Central cylinder & $213 \mathrm{bc}$ & $258 \mathrm{bc}$ \\
& Epidermis 0.02 mm from edge & $95 \mathrm{gc}$ & $14 \mathrm{cc}$ \\
Floral bud of broccoli floret & Epidermis 0.02-0.2 mm from edge & $132 \mathrm{de}$ & $43 \mathrm{cc}$ \\
& Epidermis 0.2-0.4 mm from edge & $169 \mathrm{cc}$ & $108 \mathrm{bc}$ \\
& Receptacle & $162 \mathrm{cc}$ & $65 \mathrm{cc}$ \\
& Petal & $109 \mathrm{fg}$ & $33 \mathrm{cc}$ \\
\hline
\end{tabular}

${ }^{z}$ Values within a column followed by the same lowercase letter are not significantly different $(P<0.05)$ according to the Tukey-Kramer honestly significant difference (HSD) test.

In the case of spinach leaves, parenchyma cells, occupying a large part of the spinach leaf, were more darkly stained than the mesophyll of onion scale leaves, and the luminance of both parenchyma cells and epidermis was statistically the same. The luminance values were also the same as for mid-epidermis $(0.02-0.2 \mathrm{~mm}$ from the edge) of broccoli floret stems. However, some organs in broccoli florets stained much darker than spinach leaves. The luminance of outer epidermis $(0.02 \mathrm{~mm}$ from the edge) of the stems of broccoli florets was lower than spinach leaves. However, the luminance of other sites of broccoli floret stems was more than that of the leaves. This suggests that evenly distributed cytochrome $c$ oxidase in spinach leaves and concentrated cytochrome $c$ oxidase, mainly in the epidermis, in broccoli floret stems resulted in similar cytochrome $c$ oxidase activity statistically. However, the cytochrome $c$ oxidase activity of floral buds of broccoli florets was significantly higher than that of spinach leaves. Cytochrome $c$ oxidase activity of a whole broccoli floret was estimated as $1.03 \mu \mathrm{kat} \cdot \mathrm{kg}^{-1}$ based on the data in Table 2 and the mass ratio of stems to floral buds (1.95:1). This suggests that the higher $\mathrm{O}_{2}$ uptake rate of broccoli florets compared to spinach leaves is caused by higher cytochrome $c$ oxidase activity of the floral buds. The distribution of luminance in floral buds of broccoli florets was not uniform. The luminance of the pistil was lowest. The petal was stained to the same luminance as the outer epidermis of broccoli floret stems. On the other hand, the receptacle was stained to the same luminance as the inner epidermis. Moreover, the luminance of the site was higher than that of the epidermis of onion scale leaves, and of parenchyma cells and epidermis of spinach leaves. Therefore, the higher cytochrome $c$ oxidase activity of the floral buds than the other organs was caused by the enzyme partially concentrated in pistil and petal.

RELATIONSHIP BETWEEN CELL SIZE AND CYTOCHROME $C$ OXIDASE CONCENTRATION. The cell area for which the luminance was high was relatively large (Table 3). The relationship between cross-sectional area and luminance of all the individual cells used for image analysis is shown in Fig. 2. The luminance decreased with the decrease in cross-sectional area of cytoplasm and, therefore, with the increase in staining intensity. Dali et al. (1997) indicated that the degree of cytochrome $c$ oxidase staining increased with the decrease in cross-sectional area of rat (Rattus norvegicus Berkenhout) pelvic ganglion cells. This result agrees with the data in Fig. 2 , although there are differences between animal and plant cells. Smith (1940) reported that the $\mathrm{CO}_{2}$ production rate of apples (Malus $\times$ domestica Mill.) is proportional to the number of cells per unit mass. As $\mathrm{O}_{2}$ uptake rate is assumed to be almost equal to $\mathrm{CO}_{2}$ production rate under aerobic conditions (Kader et al., 1989), the result by Smith (1940) supports the validity of the result demonstrating that the luminance per cell cytoplasm increased with the cross-sectional area per cell cytoplasm (Fig. 2) because the luminance is associated with cytochrome $c$ oxidase activity or $\mathrm{O}_{2}$ uptake rate. This suggests that the concentration of mRNA is diluted with the increase in volume per cell. This has already been disclosed by Burström (1974) using pea stems (Pisum sativum L.). The dilution also suggests a decrease in enzyme concentration including cytochrome $c$ oxidase derived from mRNA, which would lead to a reduction in enzymatic activity per mass. This agrees with the observation that broccoli florets exhibiting rapid respiration include many young, small cells and that an onion bulb, as a storage organ exhibiting slow respiration, is composed of many aged, large cells. It was considered that the difference in cytochrome $c$

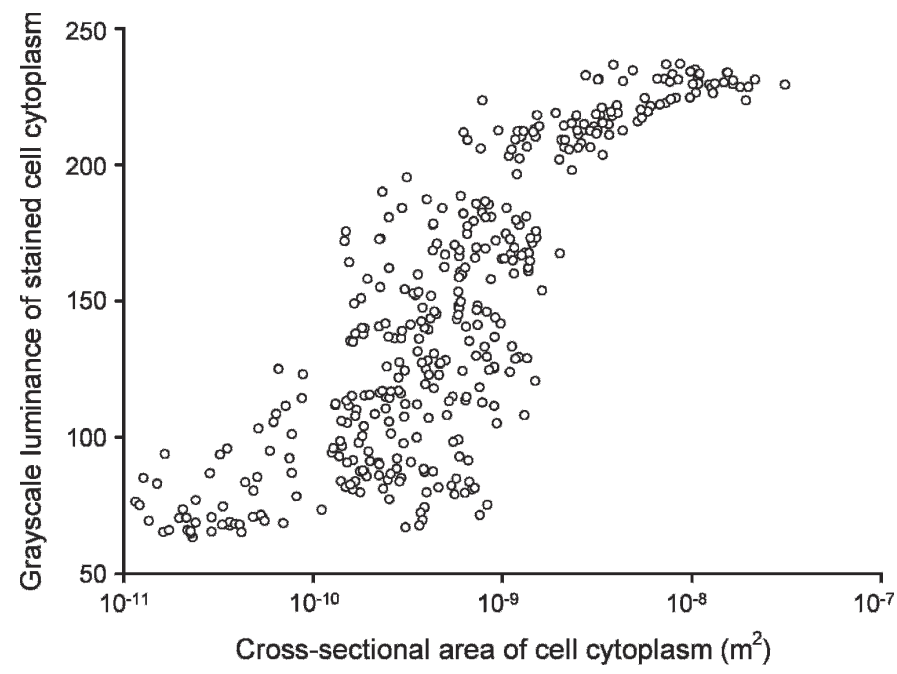

Fig. 2. Relationship between cross-sectional area and grayscale luminance of vegetable cells. 


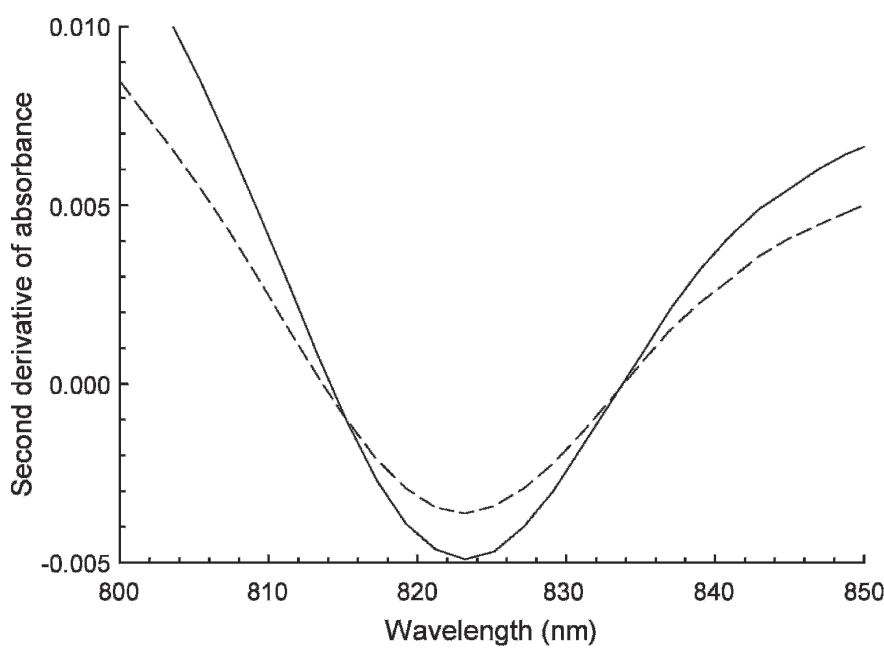

Fig. 3. Second derivative of the absorption spectrum of an onion scale leaf and a main stem of a broccoli floret, denoted by dashed and solid lines, respectively.

oxidase activity or degree of staining between vegetables is affected by the size or age of the cells because vegetables were harvested at various growing stages. According to our results, the $\mathrm{O}_{2}$ uptake rate measured by gas chromatography may be associated with harvesting stage.

DETECTION OF CYTOCHROME $C$ OXIDASE BY NONDESTRUCTIVE METHODS. The absorption spectrum of cytochrome $c$ oxidase purified from beef heart particles was first measured by Griffiths and Wharton (1961), and they found a weak band with an absorption maximum at $830 \mathrm{~nm}$ for oxidized cytochrome $c$ oxidase. Jöbsis (1977) observed the dependence of cytochrome $c$ oxidase on $\mathrm{O}_{2}$ sufficiency by spectrophotometry and reported an absorption band at $822 \mathrm{~nm}$ derived from oxidized low potential copper in cytochrome $c$ oxidase in cephalo of cats. Richaud and Denis (1984) reported an absorption band caused by copper in cytochrome $c$ oxidase at $812 \mathrm{~nm}$ using potato tubers (Solanum tuberosum L.). An adsorption band at almost the same wavelength was detected in the current study by measuring absorption spectra of vegetables. The absorption by broccoli floret stems was larger than that of onion scale leaves. Therefore, spectrophotometry can be used to gather information on cytochrome $c$ oxidase in vegetables.

The difference in absorbance between broccoli floret stems and onion scale leaves at $823 \mathrm{~nm}$ (Fig. 3) was related to the difference in degree of staining between mesophyll with thin epidermis of an onion scale leaf (Fig. 1A) and cortex of a broccoli floret stem (Fig. 1D).

\section{Conclusion}

We attempted to validate the assumption that $\mathrm{O}_{2}$ uptake rate of vegetables increases with the number of $\mathrm{O}_{2}$ adsorption sites per unit mass is dominated by cytochrome $c$ oxidase concentration as we suggested earlier (Makino et al., 1997), based on three methods of cytochrome $c$ oxidase measurement. Measurement of cytochrome $c$ oxidase activity per mass appears to be related to $\mathrm{O}_{2}$ uptake rate measured by gas chromatography. Cytochrome $c$ oxidase staining was useful for investigating the distribution of cytochrome $c$ oxidase as one of the $\mathrm{O}_{2}$ adsorption sites in a tissue. We concluded that $\mathrm{O}_{2}$ uptake rate measured by gas chromatography was related to actual concentration of cytochrome $c$ oxidase as an $\mathrm{O}_{2}$ adsorption site. However, this conclusion relies on the assumption that reactive conditions of cytochrome $c$ oxidase such as temperature, $\mathrm{pH}$ and ethylene concentration are stable as demonstrated here. In Robinson et al. (1975), the $\mathrm{CO}_{2}$ production rates of sprouting broccoli, spinach and onion at $20^{\circ} \mathrm{C}$ are 425,150 , and $8 \mathrm{mg} \cdot \mathrm{kg}^{-1} \cdot \mathrm{h}^{-1}$, respectively, and the shelf lives of them at $20^{\circ} \mathrm{C}$ (after storage under practical conditions) are 2-4, 2-5, and 7$10 \mathrm{~d}$, respectively. This suggests that the shelf life decreases with increase in respiration rate and that this rate will be useful information for estimating shelf life. Therefore, the metabolic activity and the shelf life of a horticultural product may be estimated by investigating cytochrome $c$ oxidase concentration. Measurement of the absorption band at $823 \mathrm{~nm}$ by a nondestructive method may be effective for detecting cytochrome $c$ oxidase in cortex of horticultural products.

\section{Literature Cited}

Alberts, B., D. Bray, J. Lewis, M. Raff, K. Roberts, and J.D. Watson. 1994. The respiratory chain and ATP synthase, p. 672-683. In: Molecular biology of the cell. 3rd ed. Garland Publishing, New York. Artés, F., F. Vallejo, and J.A. Martínez. 2001. Quality of broccoli as influenced by film wrapping during shipment. Eur. Food Res. Technol. 213:480-483.

Bleecker, A.B. and H.B. Kende. 2000. Ethylene: a gaseous signal molecule in plants. Annu. Rev. Cell Dev. Biol. 16:1-18.

Burström, H.G. 1974. Patterns of syntheses during internodal growth of Pisum stems. Zt. Pflanzenphysiol. 74:1-13.

Dali, W.G., R. Galindo, F. Harji, and J. Gonzales. 1997. Cytochrome oxidase staining in the major pelvic ganglion of the male rat. J. Auton. Nerv. Syst. 65:57-64.

Fonseca, S.C., F.A.R. Oliveira, and J.K. Brecht. 2002. Modelling respiration rate of fresh fruits and vegetables for modified atmosphere packaging: a review. J. Food Eng. 52:99-119.

Griffiths, D.E. and D.C. Wharton. 1961. Studies of the electron transport system. XXXV. Purification and properties of cytochrome oxidase. J. Biol. Chem. 236:1850-1856.

Jöbsis, F.F. 1977. Noninvasive, infrared monitoring of cerebral and myocardial oxygen sufficiency and circulatory parameters. Science 198:1264-1267.

Juszczuk, I.M. and A.M. Rychter. 2003. Alternative oxidase in higher plants. Acta Biochim. Pol. 50:1257-1271.

Kader, A.A. 1986. Biochemical and physiological basis for effects on controlled and modified atmospheres on fruits and vegetables. Food Technol. 40:99-100, 102-104.

Kader, A.A., D. Zagory, and E.L. Kerbel. 1989. Modified atmosphere packaging of fruits and vegetables. Crit. Rev. Food Sci. Nutr. 28:1-30.

Karovičová, J., M. Drdák, G. Grreif, and E. Hybenová. 1999. The choice of strains of Lactobacillus species for the lactic acid fermentation of vegetable juices. Eur. Food Res. Technol. 210:53-56.

Lee, C.H. and K.L. Parkin. 1998. Relationship between thiosulfinates and pink discoloration in onion extracts, as influenced by $\mathrm{pH}$. Food Chem. 61:345-350.

Maeshima, M. and T. Asahi. 1978. Purification and characterization of sweet potato cytochrome $c$ oxidase. Arch. Biochem. Biophys. 187:423-430.

Maeshima, M., I. Uritani, and T. Asahi. 1980. Effect of temperature on the activities of cytochrome $c$ oxidase and respiration in cassava root mitochondria. Agr. Biol. Chem. 44:2493-2494.

Makino, Y., K. Iwasaki, and T. Hirata. 1997. Application of transition state theory in model development for temperature dependence of respiration of fresh produce. J. Agr. Eng. Res. 67:47-59.

Michaelis, L. and M.L. Menten. 1913. Die kinetik der Invertinwirkung. Biochem. Z. 49:333-369. 
Richaud, P. and M. Denis. 1984. A near-infrared investigation of cytochrome $c$ oxidase in higher plant mitochondria. Arch. Biochem. Biophys. 232:8-16.

Robinson, J.E., K.M. Brown, and W.G. Burton. 1975. Storage characteristics of some vegetables and soft fruits. Ann. Appl. Biol. 81:399-408.

Shoham, D., M. Hübener, S. Schulze, A. Grinvald, and T. Bonhoeffer. 1997. Spatio-temporal frequency domains and their relation to cytochrome oxidase staining in cat visual cortex. Nature 385:529533.

Smith, W.H. 1940. The histological structure of the flesh of the apple in relation to growth and senescence. J. Pomol. Hort. Sci. 18:249-260.
Tajima, K. 1965. Studies on the physiology of crop plants in response to the effect of high temperature. II. Inhibition by high temperature of cytochrome $c$ oxidase activity and its restoration by phospholipid. Proc. Crop Sci. Soc. Jpn. 33:375-378.

Wong-Riley, M. 1979. Changes in the visual system of monocularly sutured or enucleated cats demonstrable with cytochrome oxidase histochemistry. Brain Res. 171:11-28.

Yonetani, T. and G.S. Ray. 1965. VI. Kinetics of the aerobic oxidation of ferrocytochrome $c$ by cytochrome $c$ oxidase. J. Biol. Chem. 240:3392-3398.

Yoshikawa, S. 2002. Cytochrome $c$ oxidase. Adv. Protein Chem. 60:341-395. 